\title{
In Utero Ventilation Augments the Left Ventricular Response to Isoproterenol and Volume Loading in Fetal Sheep
}

\author{
DAVID F. TEITEL, MICHIEL DALINGHAUS, STEVEN C. CASSIDY, BRUCE D. PAYNE, AND \\ ABRAHAM M. RUDOLPH
}

Cardiovascular Research Institute and Departments of Pediatrics, Physiology, and Obstetrics and Reproductive Sciences, University of California, San Francisco, California 94143

\begin{abstract}
In its normal circulatory environment, the fetal left ventricle can maximally increase output less than 2-fold, in contrast to the nearly 3 -fold increase that occurs at birth. Several studies have attributed this finding to fetal myocardial "immaturity," and speculated that there is a rapid maturation of the myocardium in the perinatal period. We investigated the importance of the circulatory environment itself, rather than myocardial immaturity, by measuring left ventricular output (LVO) during in utero oxygen ventilation and isoproterenol infusion. We studied seven near-term fetal sheep $\geq 2 \mathrm{~d}$ after placement of intravascular catheters, an endotracheal tube, and an electromagnetic flow transducer around the ascending aorta. We measured hemodynamic variables in the presence and absence of all combinations of oxygen ventilation, isoproterenol infusion, and volume infusion. Baseline LVO was normal (133 \pm 27 $\left.\mathrm{mL} \cdot \mathrm{kg}^{-1} \cdot \mathrm{min}^{-1}\right)$. Individually, oxygen ventilation $(136 \pm$ $\left.11 \mathrm{~mL} \cdot \mathrm{kg}^{-1} \cdot \mathrm{min}^{-1}, p<0.001\right)$ and isoproterenol $(48 \pm 11$ $\left.\mathrm{mL} \cdot \mathrm{kg}^{-1} \cdot \mathrm{min}^{-1}, p<0.05\right)$ increased LVO significantly; volume infusion did not. Their cumulative effect increased LVO nearly 3-fold (to $387 \pm 98 \mathrm{~mL} \cdot \mathrm{kg}^{-1} \cdot \mathrm{min}^{-1}$ ), similar to levels seen in the newborn lamb. Mean left atrial pressure increased above right during oxygen ventilation (from $0.05 \pm 0.54 \mathrm{kPa}$ to $0.82 \pm 0.39 \mathrm{kPa}, p \leq 0.0001)$. We conclude that the previously observed limitation in maximal LVO in the near-term fetus is primarily caused by its circulatory environment rather than relative myocardial immaturity, and speculate that a prominent Starling response is uncovered by decreases in left ventricular afterload and right ventricular constraint. (Pediatr Res 29: 466$472,1991)$
\end{abstract}

The fetal left ventricle functions in an environment of low oxygen demand and in parallel with a dominant right ventricle. Consequently, its output need not be as high as that of the newborn left ventricle (1-4). At birth, when oxygen demand increases dramatically and the systemic and pulmonary circulations separate, left ventricular output increases threefold $(5-12)$ However, studies performed in sheep suggest that the fetal left ventricle is incapable of increasing its output anywhere near levels seen in the newborn; maximal increases are less than $50 \%$ above control in response to increases in preload (13) or heart rate $(14,15)$, or during $\beta$-adrenergic stimulation (16)

Received June 5, 1990; accepted December 6, 1990.

Correspondence and reprint requests: David F. Teitel, Box 0130, University of California, San Francisco, San Francisco, CA 94143.

Supported by an NIH Program Project Grant (HL 24056) and an NIH Research Grant (HL 35842). M.D. was supported by a NATO Science Fellowship awarded by the Netherlands Organization for Scientific Research (NWO).
The basis of this limitation in the ability of the fetal left ventricle to greatly increase output (systolic performance) is controversial. Several studies point to myocardial immaturity: incomplete development of sarcomeres (17-21), decreased functioning of $\beta$-receptors $(22,23)$, and myofibrillar disarray $(24,25)$ have all been implicated. Although fetal myocardium is certainly immature relative to that of the adult, none of these factors have been shown to change immediately at birth. In addition, many indices of systolic performance are increased in the newborn left ventricle relative to that of the adult $(11,12)$, so that myocardial immaturity may not necessarily be associated with impaired ventricular function. It is remarkable that both the prematurely born animal (26-28) and human (29), which have not been exposed to prenatal hormone surges and labor to accelerate myocardial maturation, are capable of greatly increasing left ventricular output in response to a patent ductus arteriosus. In addition, recent studies of fetal sheep undergoing oxygen ventilation in utero have shown a doubling of left ventricular output $(3,30)$, and other determinants of output such as septal compliance (31) have been shown to change in the perinatal period.

Thus, left ventricular output may be limited in the fetus more because of its "circulatory environment" (the combination of a parallel circulation with central shunts, a dominant hypertrophied right ventricle that ejects more output and fills under similar pressures, a pulmonary vascular bed that is markedly constricted and that returns a very limited amount of blood to the left atrium and ventricle, and a highly compliant fetoplacental vascular bed that can absorb increases in volume that would otherwise increase left ventricular filling volume) than because of myocardial immaturity. For example, the fetal left ventricle has a very limited ability to increase output via the Frank-Starling mechanism (13), with a plateau occurring at 5-7 mm Hg. However, Hawkins et al. (32) have shown that some of this limitation is caused by a concomitant increase in afterload; if afterload is controlled, left ventricular output continues to rise at filling pressures of $10 \mathrm{~mm} \mathrm{Hg}$. In addition, high right ventricular filling and ejecting pressures may constrain left ventricular performance both in diastole and systole (33-36).

We undertook the present study to determine whether the near-term (approximately 0.9 gestation) fetal left ventricle, functioning in a simulated "postnatal circulatory environment" (abolition of most central shunts with a small left to right shunt through the ductus arteriosus, a dominant left ventricle ejecting somewhat more blood than the right under higher filling pressures, a dilated pulmonary vascular bed returning a large amount of blood to the left atrium and ventricle, and a decrease in the fetoplacental vascular bed), is capable of increasing its output to levels similar to those seen in the newborn. We simulated the immediate postnatal circulatory environment in utero by studying chronically instrumented fetal sheep during oxygen ventilation (3). We also determined the effects of isoproterenol infusion, 
to simulate the important catecholamine surge at birth $(28,37)$ and volume loading. We measured left ventricular output, vascular pressures, and heart rate, and determined the individual and combined effects of each intervention on these variables.

\section{MATERIALS AND METHODS}

Seven fetal sheep were studied at $135.4 \pm 0.8 \mathrm{~d}$ of gestation (term is about $145 \mathrm{~d}$ ). The fetuses were of normal weight (3.6 \pm $0.6 \mathrm{~kg}$ ) and had normal blood gases and arterial oxygen contents (see Results) at the onset of the study. The study was approved by the Committee of Animal Research at the University of California, San Francisco.

Surgical preparation. The ewe underwent a midline laparotomy under spinal (1\% tetracaine hydrochloride) and supplemental i.v. (ketamine hydrochloride) anesthesia. The fetus also received local anesthesia $(0.25 \%$ lidocaine hydrochloride) for each skin incision. A fetal hind limb was exposed through a small uterine incision and polyvinyl catheters were advanced to the descending aorta and inferior vena cava via the pedal artery and vein, respectively. A large bore polyvinyl catheter was placed in the amniotic cavity for a zero pressure reference, and the skin and uterine incisions were closed. A second uterine incision was then made over the left chest of the fetus and a left lateral thoracotomy was performed in the 4th intercostal space. A catheter was placed directly into the left atrium using a special needle-cannula assembly (38), and an electromagnetic flow transducer [Statham Instruments, Oxnard, CA] was placed around the ascending aorta [this underestimates left ventricular output by coronary flow, which is approximately $3 \%$ of combined ventricular output (3)]. An $8 \mathrm{~F}$ multiple side-hole polyvinyl catheter was left in the pleural cavity for drainage, the pericardium was left open, and the thoracotomy was closed. Through the same uterine incision, the neck was exposed in the midline. The trachea was ligated proximally, and an endotracheal tube (4.5 $\mathrm{mm}$ inner diameter) was inserted directly and advanced to the region of the carina. The proximal end of the tube was attached to two pieces of $12 \mathrm{~F}$ polyvinyl tubing via a $Y$ connector, and the tubing was filled with $0.9 \% \mathrm{NaCl}$ solution. One piece of the $12 \mathrm{~F}$ tubing was sealed and the other was connected to a third piece of tubing that was placed in the amniotic cavity to allow free drainage of tracheal fluid postoperatively. Polyvinyl catheters were placed in a carotid artery and jugular vein and advanced to the ascending aorta and right atrium, respectively. The neck and uterine incisions were then closed. Antibiotics (400 mg of kanamycin sulfate and 1 million units of penicillin $G$ potassium) were instilled in the amniotic cavity and $0.9 \%$ warmed $\mathrm{NaCl}$ solution was added to replace lost amniotic fluid. All vascular catheters were filled with heparin sodium $(1000 \mathrm{U} / \mathrm{mL})$, sealed, and exteriorized along with the tubing to the left flank of the ewe. The abdominal incision was closed in layers and the ewe was returned to the cage for recovery. Antibiotics (400 mg of kanamycin sulfate and 1 million units of penicillin $G$ potassium) were administered i.v. to the ewe and into the amniotic cavity daily.

Experimental protocol. Forty-eight to $72 \mathrm{~h}$ after surgery, the ewe was placed in a study cage and allowed free access to alfalfa pellets and water. Vascular catheters (ascending aortic, left atrial, and right atrial) were connected to Statham P23Db strain-gauge transducers, and the ascending aortic flow transducer was connected to a Statham SP2202 flowmeter. Pressures and flow were recorded continuously by a direct-writing polygraph (Gould Instruments, San Jose, CA), which was in turn connected to a Macintosh II computer (Apple Computer, Cupertino, CA) via an analog-digital data acquisition card (National Instruments, Austin, TX). Data from each channel were acquired on disk at a sampling rate of $200 \mathrm{~Hz}$ (Lab View; National Instruments).

We acquired data during stable hemodynamic conditions in eight states, which were all combinations of three conditions: \pm oxygen ventilation, \pm isoproterenol infusion, \pm volume infusion (Fig. 1). The order of oxygen ventilation and isoproterenol

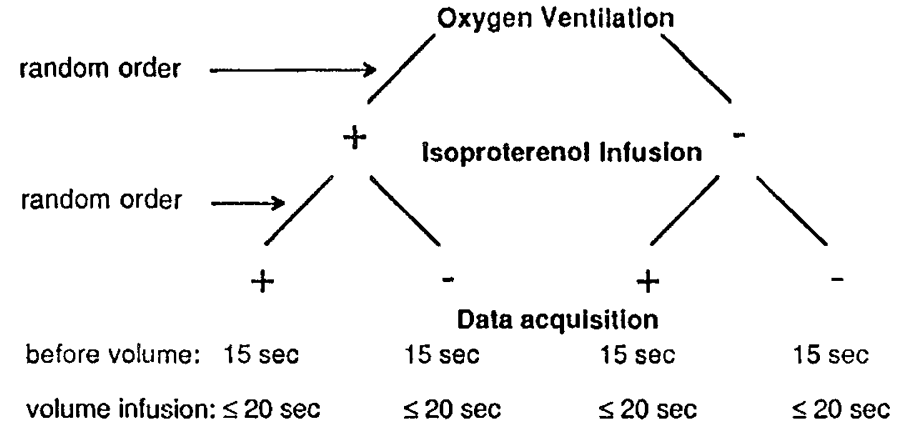

Fig. 1. Schematic representation of the study protocol.

infusion were randomly varied, but the volume infusion studies always immediately followed those during the corresponding state without volume infusion, because measurements for the two states were made during the same period of data acquisition. The state in which measurements were made in the absence of all interventions, called baseline hereafter, most closely approximates the hemodynamic condition of the undisturbed fetal sheep. All measurements were made during parasympathetic blockade using atropine $(0.4 \mathrm{mg}$ i.v. every $30 \mathrm{~min})$ to abolish the vagal-mediated decrease in heart rate that occurs during volume infusion.

We also measured systemic arterial $\mathrm{pH}, \mathrm{PCO}_{2}$, and $\mathrm{PO}_{2}$ (Corning $158 \mathrm{pH} /$ blood gas analyzer, Corning Medical, Medfield, $\mathrm{MA}$ ), and $\mathrm{Hb}$ concentration and oxygen saturation (Radiometer OSM2 hemoximeter, Copenhagen, Denmark) at least once during and once without oxygen ventilation.

Oxygen ventilation. To initiate oxygen ventilation, the two polyvinyl tubes connected to the tracheal tube were opened, drained, and connected to a volume-regulated ventilator (Harvard Apparatus Ltd., Edenbridge, England). To ensure a maximal decrease in pulmonary vascular resistance, $100 \%$ oxygen was used. The ventilation settings were initially adjusted to deliver an inspiratory:expiratory ratio of $0.8: 1$, a respiratory rate of $55-60 / \mathrm{min}$, and a tidal volume of about $20-30 \mathrm{~mL}$, similar to that used in our previous experiments $(3,39)$. Positive endexpiratory pressure was applied to counterbalance amniotic pressure. Arterial blood gases and $\mathrm{Hb}$ oxygen saturations were obtained, and the ventilator settings were adjusted until acceptable values were reached ( $\mathrm{Hb}$ oxygen saturation $\geq 0.90$ and $\mathrm{PCO}_{2} \leq$ $8.0 \mathrm{kPa}$ ), except in one sheep, in which the maximal attainable saturation was 0.81 . Oxygen ventilation was continued for at least $15 \mathrm{~min}$ before data acquisition.

Isoproterenol infusion. During each ventilation condition $( \pm$ oxygen ventilation), data were acquired in the absence of and during a peripheral venous infusion of isoproterenol $(1 \mu \mathrm{g}$. $\mathrm{min}^{-1}$ ), in a random order, each after $15 \mathrm{~min}$ of hemodynamic stability.

Volume infusion. During the continuous acquisition of data in each of the four combinations of \pm oxygen ventilation and \pm isoproterenol infusion (Fig. 1), volume was infused after $15 \mathrm{~s}$ of control measurements (-volume infusion). Maternal or fetal sheep blood was infused rapidly into the left atrium at a rate of $5 \mathrm{~mL} \cdot \mathrm{s}^{-1}$. During the infusion of blood, ascending aortic blood flow was closely monitored; the infusion was discontinued when flow began to fall. This always occurred between 10 and $20 \mathrm{~s}$ of infusion, so that $50-100 \mathrm{~mL}$ of blood was infused, approximating a volume load of $14-28 \mathrm{~mL} \cdot \mathrm{kg}^{-1}$. Left atrial pressure was monitored during the control measurement and after discontinuing the infusion because the catheter was used for the infusion. At the end of data acquisition, an equivalent volume of blood was removed from the fetus, which was then allowed to recover for at least $20 \mathrm{~min}$ before the next condition. For analysis, the last 5 $\mathrm{s}$ of data obtained before the volume infusion were averaged and constituted the "-volume" condition, and the data obtained at peak ascending aortic blood flow during the infusion constituted 
the "+volume" condition. However, because left atrial pressure measurements could not be obtained at peak blood flow for the "+volume" conditions, data for both left and right atrial pressures instead were obtained at discontinuation of the infusion, and represent pressures somewhat greater than those at peak flow.

Statistical analysis. All data are reported as mean \pm SD. All regression coefficients are reported with corresponding SEM. Statistical significance was assumed present when the probability of the value obtained for any test statistic was $\leq 0.05$.

To test whether significant differences in ascending aortic blood flow, heart rate, or mean systemic arterial pressure were present among the eight states or among sheep, we used a multiple linear regression analysis using dummy variables coded by effect $(40,41)$. The regression model was

$$
\begin{aligned}
\mathrm{Y}=\mathrm{b}_{0}+\mathrm{b}_{\mathrm{O}_{2}} \mathrm{O}_{2}+\mathrm{b}_{\mathrm{i}} \mathrm{ISO}+\mathrm{b}_{\mathrm{v}} \mathrm{VOL} \\
+\mathrm{b}_{\mathrm{O}_{2} \mathrm{O}} \mathrm{O}_{2} \cdot \mathrm{I}+\mathrm{b}_{\mathrm{O}_{2} \mathrm{v}} \mathrm{O}_{2} \cdot \mathrm{V}+\mathrm{b}_{\mathrm{iv}} \mathrm{I} \cdot \mathrm{V}+\sum \mathrm{b}_{\mathrm{j}}^{\mathrm{s}} \mathrm{S}_{\mathrm{j}}
\end{aligned}
$$

where $\mathrm{Y}$ is the dependent variable of interest (ascending aortic blood flow, heart rate, or mean systemic arterial pressure); $b_{0}$ (the intercept of the equation) is its mean value over all the observations (an observation is the measurement of that dependent variable for each animal during each state; thus there are 56 observations of each dependent variable); $\mathrm{O}_{2}$, isoproterenol (ISO), volume infusion (VOL), etc. represent the dummy variables; and the $b$ associated with each dummy variable represents its coefficient.

Coding of the dummy variables was done using the effects model: each was assigned a value of $-1,0$, or 1 for each observation (41). In this manner, the dummy variable $\mathrm{O}_{2}$ was assigned a value of 1 if the observation was made during oxygen ventilation and -1 otherwise (-oxygen ventilation). ISO and VOL were assigned values similarly. To determine whether interactive effects occurred when two or more interventions $\left(\mathrm{O}_{2}\right.$, ISO, and/or VOL) were performed during an observation, we defined three interactive dummy variables, $\mathrm{O}_{2} \cdot \mathrm{I}, \mathrm{O}_{2} \cdot \mathrm{V}$, and $\mathrm{I}$. $\mathrm{V}$. They were assigned a value of 1 when the interaction was present and -1 when it was not. For example, if an observation were made during oxygen ventilation and volume infusion, the variable $\mathrm{O}_{2} \cdot V$ would be assigned a value of 1 and the other three variables would be assigned values of -1 . The interaction of all three interventions simultaneously $\left(\mathrm{O}_{2} \cdot \mathrm{I} \cdot \mathrm{V}\right)$ cannot easily be interpreted from a physiologic standpoint; thus, its effects on the dependent variables are not included in the equation, but within the residual error (41). We defined a set of dummy variables, $S_{1}$ through $S_{6}$, to determine the between-sheep variability for each dependent variable (42). The first sheep was assigned a set of $S_{j}$

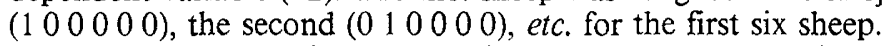
The 7 th sheep was assigned a set of $S_{j}(-1-1-1-1-1-1)$.

The coefficients for each dummy variable estimate the changes from the overall mean value associated with that variable (for example, $b_{v}$ is an estimate of the effect of volume infusion on the overall mean value). The mean baseline value of the dependent variable is its value when all intervention and interactive variables are assigned a value of -1 and all between-sheep variables a value of 0 . The mean value of any intervention is similarly defined, except that the variable for that intervention is given a value of 1 rather than -1 . The effect of any intervention or interaction on the mean baseline value of the dependent variable can be determined by doubling the value of its coefficient.

To determine the statistical significance of any variable or set of variables, an $F$ test was performed by dividing the mean square of that variable or set of variables by the mean square residual (41). For the individual interventions $\left(\mathrm{O}_{2}\right.$, isoproterenol, and volume infusion) the mean square is equal to the type III sum of squares of that variable (the degrees of freedom for each variable in a linear regression model being 1 ). For the set of interactive variables, the mean square was calculated by summing the type III sum of squares of the three interactive variables and dividing by 3 . For the between-sheep effects, a similar calculation was performed, but the combined sum of squares was divided by 6 . In addition, the SD of the coefficients of $S_{1}-S_{6}$ was calculated as a measure of between-sheep variability (43). Multiple comparisons between coefficients of the dummy variables were performed by the Student-Neuman-Keuls test (44).

To evaluate the effects of oxygen ventilation on blood gases and on the mean pressure difference between the left atrium and the right atrium (an estimate of the difference in filling pressures between the left and right ventricles), all data ( \pm volume infusion and \pm isoproterenol infusion) within an oxygen ventilation state were combined and paired $t$ tests were performed.

\section{RESULTS}

Ascending aortic blood flow. Mean ascending aortic blood flow in the baseline state was normal $\left(133 \pm 27 \mathrm{~mL} \cdot \mathrm{kg}^{-1} \cdot \mathrm{min}^{-1}\right)$ for near-term fetal sheep $(1,3,4)$. Figure 2 presents ascending aortic blood flow in each state of observation. Table 1 presents the values of the coefficients of the multiple regression analysis and their statistical significance, and Table 2 presents a comparison of the measured and predicted (from the regression model) mean values for each condition.

There were no significant interactive effects (Table 1), so that the effect of each intervention can be considered independently. Volume infusion did not increase ascending aortic blood flow significantly (the mean predicted effect would increase output by $36 \mathrm{~mL} \cdot \mathrm{kg}^{-1} \cdot \mathrm{min}^{-1}$, to 1.27 times baseline), whereas isoproterenol (mean increase of $48 \mathrm{~mL} \cdot \mathrm{kg}^{-1} \cdot \mathrm{min}^{-1}$, to 1.36 times baseline) and oxygen ventilation (mean increase of $136 \mathrm{~mL} \cdot \mathrm{kg}^{-1} \cdot \mathrm{min}^{-1}$, to 2.02 times baseline) did. The effect of oxygen ventilation was greater than that of isoproterenol $(p<0.001)$. The combination of all three interventions would increase mean ascending aortic blood flow by $255 \mathrm{~mL} \cdot \mathrm{kg}^{-1} \cdot \mathrm{min}^{-1}$, to 2.91 times baseline. From Table 2 it can be seen that the measured and predicted values in each condition were within $1 \mathrm{~mL} \cdot \mathrm{kg}^{-1} \cdot \mathrm{min}^{-1}$, demonstrating that the regression equation is an accurate model of the experiment.

Heart rate. Data are presented (Fig. 3, Table 3) similarly to those of ascending aortic blood flow. Baseline heart rate was 245 $\pm 56 \mathrm{~min}^{-1}$, much higher than normal resting fetal values (2), because of the parasympathetic blockade. Of the interventions, only isoproterenol changed heart rate significantly (mean predicted increase of $40 \mathrm{~min}^{-1}$, to 1.15 times baseline). During oxygen ventilation, isoproterenol had a somewhat greater effect than in its absence (-oxygen ventilation).

Vascular pressures. Mean systemic arterial pressure data (Fig. 4, Table 4) are also presented similarly to those of ascending aortic blood low. Of the interventions, only volume infusion changed mean systemic arterial pressure significantly (mean increase of $2.0 \mathrm{kPa}$, to 1.35 times baseline). There was no interactive effect; that is, the effect of the volume infusion was the same in the presence and absence of oxygen ventilation and isoproterenol infusion.

Left atrial and right atrial pressures are presented in Table 5. These raw data were not analyzed statistically for two reasons. First, the pressures for the volume infusion conditions are not simultaneous with the data obtained at peak ascending aortic flow, as explained in Materials and Methods. Second, oxygen ventilation is probably associated with alterations in left and right ventricular compliances as left ventricular filling increases relative to right and pulmonary vascular resistance falls rapidly (3), so that comparable pressures cannot be considered indicators of comparable end-diastolic volumes. However, as an indicator of increased left ventricular filling relative to right, we compared the mean pressure difference between the left and right atrium. We found that there was no significant pressure difference before oxygen ventilation, but left atrial pressure exceeded right by 0.82 $\pm 0.39 \mathrm{kPa}$ during oxygen ventilation $(p \leq 0.0001)$.

Blood gases and vascular pressures. Systemic arterial blood 


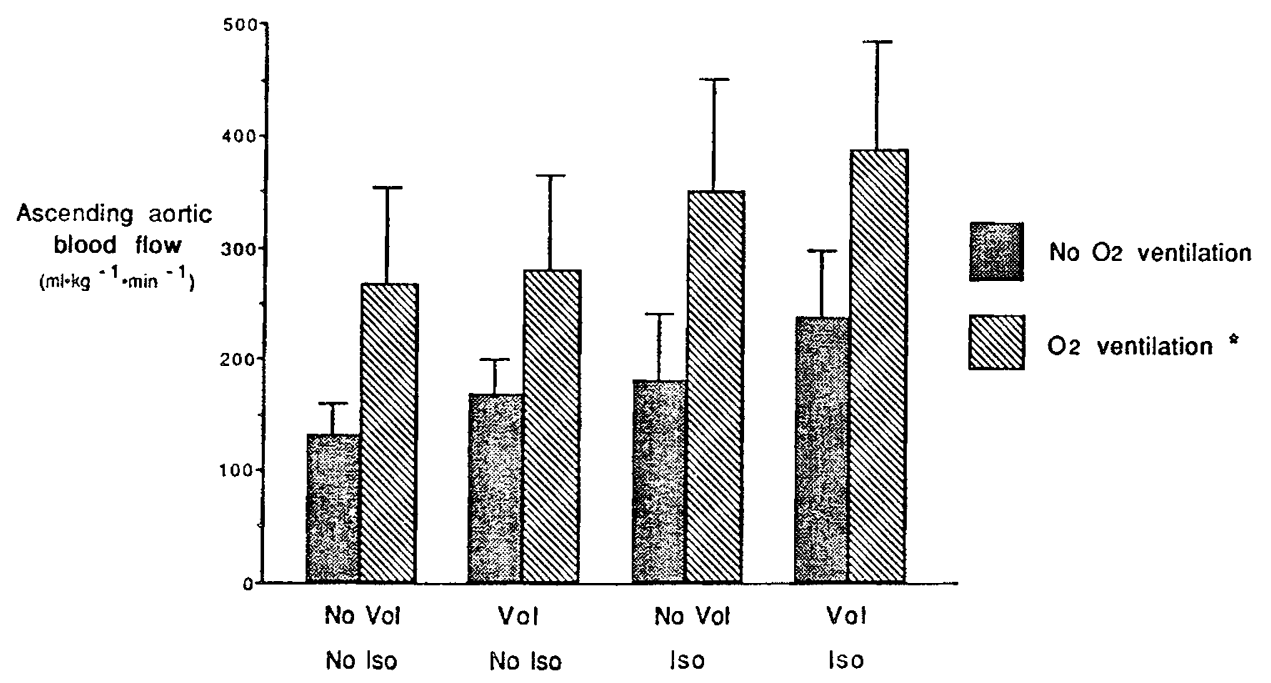

Fig. 2. Ascending aortic blood flow in the presence and absence of each intervention. Data are presented as the mean \pm 1 SD. ${ }^{*}$, the presence of that intervention significantly increases flow.

Table 1. Ascending aortic blood flow: results of multiple linear regression analysis*

\begin{tabular}{|c|c|c|c|c|c|c|c|c|c|c|c|c|c|}
\hline \multirow[b]{2}{*}{ Variable } & \multirow[b]{2}{*}{$b_{0}$} & \multicolumn{3}{|c|}{ Interventions } & \multicolumn{3}{|c|}{ Interactions } & \multicolumn{6}{|c|}{ Between sheep } \\
\hline & & $\mathrm{O}_{2}$ & ISO & VOL & $\mathrm{O}_{2} \cdot \mathrm{I}$ & $\mathrm{O}_{2} \cdot \mathrm{V}$ & $\mathrm{I} \cdot \mathrm{V}$ & S1 & $\mathrm{S} 2$ & S3 & $\mathrm{S} 4$ & S5 & S6 \\
\hline $\begin{array}{l}\mathrm{b} \\
\text { SEM } \\
p(F \text { value })\end{array}$ & 260 & $\begin{array}{l}68 \\
9.4 \\
<0.001 \dagger\end{array}$ & $\begin{array}{c}24 \\
9.4 \\
<0.02\end{array}$ & $\begin{array}{c}18 \\
9.4 \\
>0.05\end{array}$ & $\begin{array}{l}17 \\
10.9 \\
>0.10\end{array}$ & $\begin{array}{c}-11 \\
10.9 \\
>0.30\end{array}$ & $\begin{array}{l}11 \\
10.9 \\
>0.30\end{array}$ & $\begin{array}{c}-22 \\
13.3\end{array}$ & $\begin{array}{c}7 \\
13.3\end{array}$ & $\begin{array}{c}-43 \\
13.3 \\
\text { combinec }\end{array}$ & $\begin{array}{c}86 \\
2.0 \\
<0.0001\end{array}$ & $\begin{array}{c}-66 \\
13.3\end{array}$ & $\begin{array}{l}82 \\
13.3\end{array}$ \\
\hline
\end{tabular}

${ }^{*}$ The coefficients $b\left(b_{0}\right.$ : intercept; $\mathrm{O}_{2}$ : oxygen ventilation; ISO: isoproterenol infusion; VOL: volume infusion; $\mathrm{O}_{2} \cdot \mathrm{I}: \mathrm{O}_{2}$ and ISO; $\mathrm{O}_{2} \cdot \mathrm{V}: \mathrm{O}_{2}$ and VOL; I. V: ISO and VOL; S1 through S2: between-sheep variables) are in $\mathrm{mL} \cdot \mathrm{kg}^{-1} \cdot \mathrm{min}^{-1}$. The regression equation was statistically significant $(p<$ 0.0001 ), with a correlation coefficient of 0.94 . The SD of the between-sheep coefficients was $64.1 \mathrm{~mL} \cdot \mathrm{kg}^{-1} \cdot \mathrm{min}^{-1}$. The $p$ values for significant effects are in boldface.

$\dagger$ The effect of $\mathrm{O}_{2}$ was significantly greater than that of ISO $(p<0.001$, Student-Neuman-Keuls test).

Table 2. Measured and predicted (by multiple linear regression analysis) of mean ascending aortic blood flow in $\mathrm{mL} \cdot \mathrm{kg}^{-1}$.

\begin{tabular}{cccccc}
\hline & \multicolumn{3}{c}{ min $^{-1}$} & & \\
& \multicolumn{2}{c}{-Isoproterenol } & & \multicolumn{2}{c}{ +Isoproterenol } \\
\cline { 2 - 3 } \cline { 5 - 6 } & -Volume & +Volume & & -Volume & +Volume \\
\hline$-\mathrm{O}_{2}$ Ventilation & & & & \\
Measured & $133 \pm 27$ & $169 \pm 31$ & $181 \pm 60$ & $237 \pm 59$ \\
Predicted & 133 & 170 & 181 & 238 \\
$+\mathrm{O}_{2}$ Ventilation & & & & \\
$\quad$ Measured & $269 \pm 85$ & $281 \pm 82$ & $350 \pm 100$ & $387 \pm 98$ \\
Predicted & 270 & 282 & 350 & 388 \\
\hline
\end{tabular}

$\mathrm{pH}$ and $\mathrm{PCO}_{2}$ were not different with and without oxygen ventilation (Table 6). Oxygen content, $\mathrm{PO}_{2}$, and $\mathrm{Hb}$ oxygen saturation were significantly greater during oxygen ventilation, at levels similar to those described previously in fetal sheep ventilated in utero (3).

\section{DISCUSSION}

In its normal circulatory environment, the fetal left ventricle can maximally increase its output much less than 2-fold (1316). During in utero oxygen ventilation alone, however, the fetal left ventricle doubles its output $(3,30)$. We have extended these studies by.performing in utero oxygen ventilation in conjunction with $\beta$-adrenergic stimulation and volume loading, and found that the fetal left ventricle is capable of nearly tripling its output above baseline levels. Moreover, this study probably underestimates the fractional increase above resting fetal levels: our baseline measurements were performed during parasympathetic blockade, which increased heart rate considerably, and probably increased output to some degree as well $(14,45)$. This 3 -fold increase in left ventricular output is very similar to that which occurs at birth $(46,47)$, although absolute left ventricular output at birth varies widely (from 248 to $428 \mathrm{~mL} \cdot \mathrm{kg}^{-1} \cdot \mathrm{min}^{-1}$ ) among different laboratories using different techniques $(5-12)$. We have previously measured left ventricular output in the newborn lamb in the same laboratory using the same technique (ascending aortic electromagnetic flow transducer), both at rest and during isoproterenol infusion (8). In that study, left ventricular output was $265 \pm 54 \mathrm{~mL} \cdot \mathrm{kg}^{-1} \cdot \mathrm{min}^{-1}$ at rest and increased to $302 \pm 67$ $\mathrm{mL} \cdot \mathrm{kg}^{-1} \cdot \mathrm{min}^{-1}$ during isoproterenol infusion: these values are remarkably similar to output measured in the current study in the fetus during oxygen ventilation alone $\left(269 \pm 85 \mathrm{~mL} \cdot \mathrm{kg}^{-1}\right.$. $\left.\mathrm{min}^{-1}\right)$ and during oxygen ventilation and isoproterenol infusion $\left(350 \pm 100 \mathrm{~mL} \cdot \mathrm{kg}^{-1} \cdot \mathrm{min}^{-1}\right)$, respectively.

We performed this experimental protocol to stimulate the postnatal circulatory environment in utero. We have previously shown that oxygen ventilation in utero creates a central circulatory pattern that is identical to the immediate postnatal circulation (3). In addition, the newborn left ventricle functions under significant $\beta$-adrenergic stimulation $(8,37)$, which is essential to the increase in output at birth (28), and at higher filling pressures $(6,11)$ than before birth, so we performed the studies during isoproterenol infusion and volume loading in addition to oxygen ventilation. We found that oxygen ventilation and isoproterenol increased left ventricular output, but not volume infusion, and that the effect of oxygen ventilation far exceeded that of isoproterenol. Their cumulative effect increased output to newborn levels. It is thus apparent that a major factor limiting left ventricular performance in the fetus is its circulatory environment rather than relative myocardial immaturity, although it is still possible that the addition of some maturation process would allow the ventricle to perform at even greater levels.

This ability of the fetal left ventricle to achieve outputs equal 


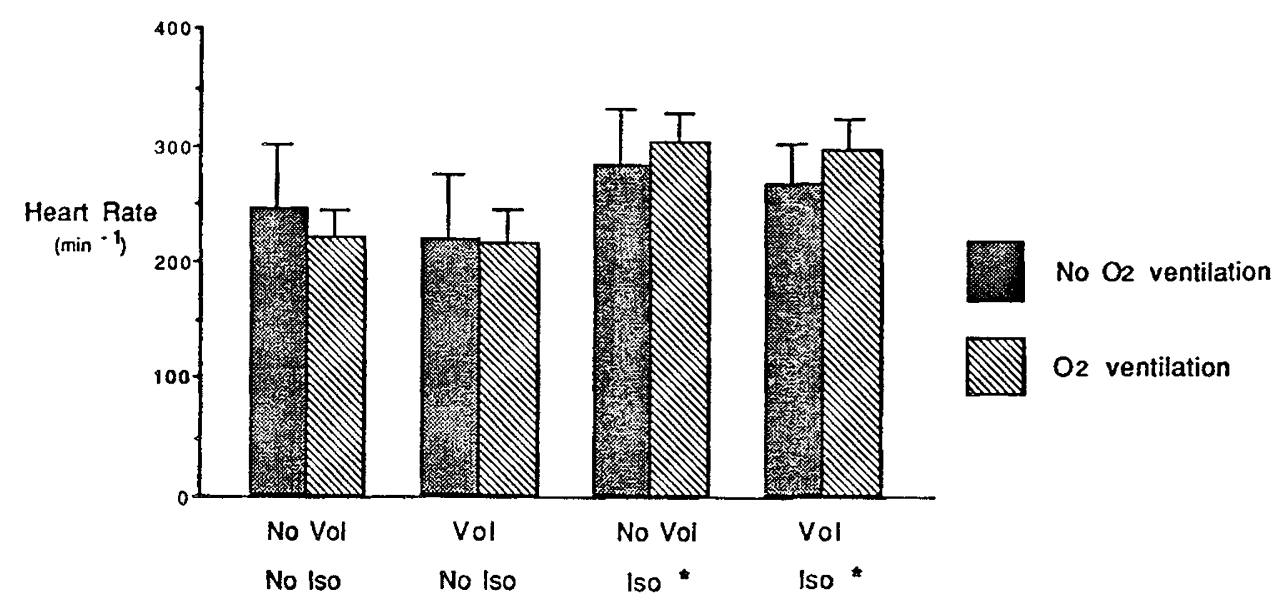

Fig. 3. Heart rate in the presence and absence of each intervention. Data are presented as the mean $\pm 1 \mathrm{SD} .{ }^{*}$, the presence of that intervention significantly increases heart rate.

Table 3. Heart rate: results of the multiple linear regression analysis*

\begin{tabular}{|c|c|c|c|c|c|c|c|c|c|c|c|c|c|}
\hline \multirow[b]{2}{*}{ Variable } & \multirow[b]{2}{*}{$b_{0}$} & \multicolumn{3}{|c|}{ Interventions } & \multicolumn{3}{|c|}{ Interactions } & \multicolumn{6}{|c|}{ Between sheep } \\
\hline & & $\mathrm{O}_{2}$ & ISO & VOL & $\mathrm{O}_{2} \cdot \mathrm{I}$ & $\mathrm{O}_{2} \cdot \mathrm{V}$ & I. V & S1 & $\mathrm{S} 2$ & $\mathrm{~S} 3$ & S4 & S5 & S6 \\
\hline $\begin{array}{l}\mathrm{b} \\
\text { SEM } \\
p(F \text { value })\end{array}$ & 269 & $\begin{array}{c}-10 \\
6.8 \\
>0.10\end{array}$ & $\begin{array}{l}20 \\
6.8 \\
<0.005\end{array}$ & $\begin{array}{c}-11 \\
\quad 6.8 \\
>0.10\end{array}$ & $\begin{array}{c}18 \\
7.9 \\
<0.05\end{array}$ & $\begin{array}{l}7 \\
7.9 \\
>0.40\end{array}$ & $\begin{array}{l}2 \\
7.9 \\
>0.80\end{array}$ & $\begin{array}{c}-35 \\
9.7\end{array}$ & $\begin{array}{l}29 \\
9.7\end{array}$ & $\begin{array}{c}28 \\
9.7 \\
\text { nbined }\end{array}$ & $\begin{array}{c}7 \\
2.0 \\
<0.00\end{array}$ & $\begin{array}{r}-30 \\
9.7\end{array}$ & $\begin{array}{l}-3 \\
9.7\end{array}$ \\
\hline
\end{tabular}

* The coefficients $\mathrm{b}$ (see Table 1 for abbreviations) are in $\min ^{-1}$. The regression equation was statistically significant $(p<0.0001)$, with a correlation coefficient of 0.84 . The SD of the between-sheep coefficients was $27.6 \mathrm{~min}^{-1}$. The $p$ values for significant effects are in boldface.

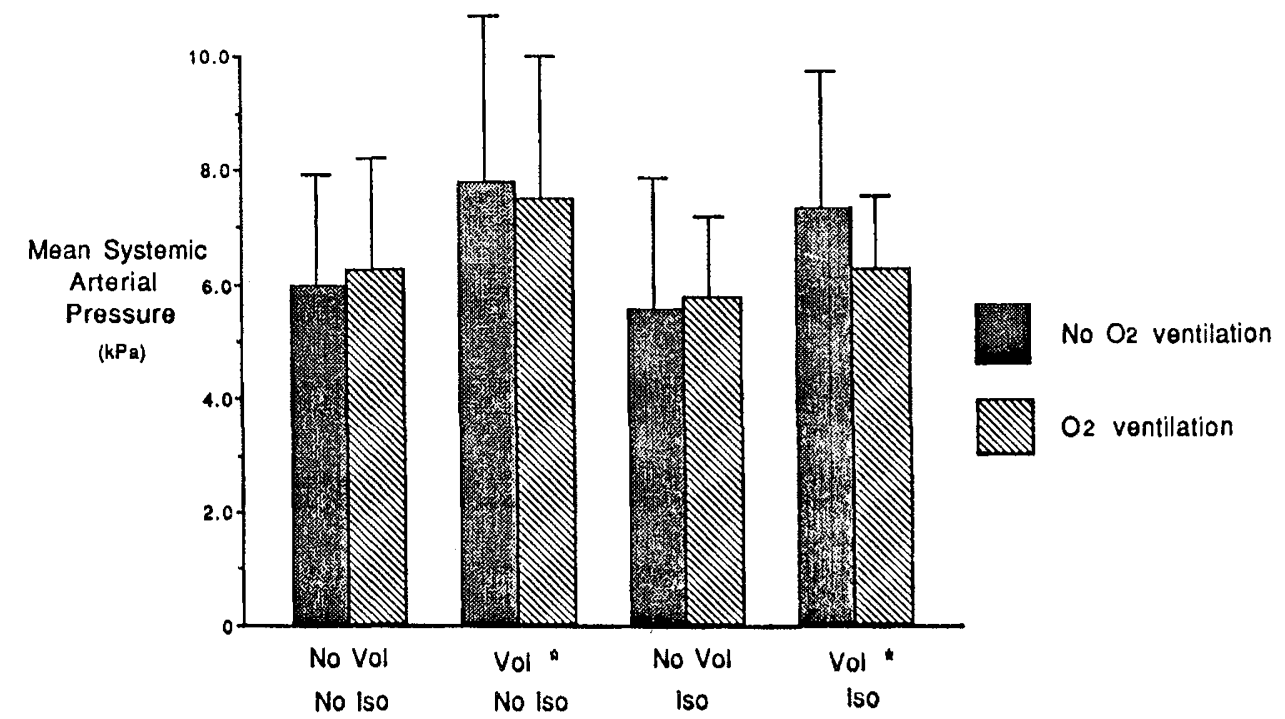

Fig. 4. Mean systemic arterial pressure in the presence and absence of each intervention. Data are presented as the mean \pm 1 SD. ${ }^{*}$, the presence of that intervention significantly increases pressure.

Table 4. Mean systemic arterial pressure: results of multiple linear regression analysis*

\begin{tabular}{|c|c|c|c|c|c|c|c|c|c|c|c|c|c|}
\hline \multirow[b]{2}{*}{ Variable } & \multirow[b]{2}{*}{$\mathrm{b}_{0}$} & \multicolumn{3}{|c|}{ Interventions } & \multicolumn{3}{|c|}{ Interactions } & \multicolumn{6}{|c|}{ Between sheep } \\
\hline & & $\mathrm{O}_{2}$ & ISO & VOL & $\mathrm{O}_{2} \cdot \mathrm{I}$ & $\mathrm{O}_{2} \cdot \mathrm{V}$ & $\mathrm{I} \cdot \mathrm{V}$ & S1 & $\mathrm{S} 2$ & S3 & S4 & $\mathrm{S} 5$ & S6 \\
\hline $\mathrm{b}$ & 6.1 & 0.2 & -0.1 & 1.0 & -0.2 & -0.5 & -0.2 & -0.1 & 0.4 & -3.1 & 2.0 & 2.5 & -1.4 \\
\hline SEM & & 0.3 & 0.3 & 0.3 & 0.3 & 0.3 & 0.3 & 0.4 & 0.4 & 0.4 & 2.0 & 0.4 & 0.4 \\
\hline$p(F$ value $)$ & & $>0.40$ & $>0.60$ & $<0.001$ & $>0.50$ & $>0.10$ & $>0.45$ & \multicolumn{6}{|c|}{ combined: $<0.0001$} \\
\hline
\end{tabular}

* The coefficients $\mathrm{b}$ (see Table 1 for abbreviations) are in $\mathrm{kPa}$. The regression equation was statistically significant $(p<0.0001)$, with a correlation coefficient of 0.90 . The SD of the between-sheep coefficients was $2.10 \mathrm{kPa} . p$ values of significant effects are in boldface.

to those of the newborn contradicts the hypothesis that it is functionally immature relative to the newborn, and supports several studies that have shown that the preterm left ventricle functions at a high level of ventricular performance $(27,28,30$,
48). The fetal myocardium is indeed immature: various indices of in vivo and in vitro performance show limitation in function of fetal myocytes, and this limitation can be correlated with fewer and poorly organized contractile elements $(24,25)$, immaturity 
Table 5. Left and right atrial pressures in $\mathrm{kPa}$

\begin{tabular}{lccccc}
\hline & \multicolumn{2}{c}{-Isoproterenol } & & \multicolumn{2}{c}{ tIsoproterenol } \\
\cline { 2 - 3 } \cline { 5 - 6 } & -Volume & +Volume & & -Volume & +Volume \\
\hline$-\mathrm{O}_{2}$ ventilation & & & & & \\
$\quad$ Left atrial & $0.15 \pm 0.59$ & $1.27 \pm 1.06$ & $0.25 \pm 0.39$ & $1.34 \pm 1.01$ \\
$\quad$ Right atrial & $0.48 \pm 0.65$ & $0.74 \pm 0.90$ & & $0.15 \pm 0.51$ & $0.87 \pm 0.82$ \\
$+\mathrm{O}_{2}$ ventilation & & & & & \\
$\quad$ Left atrial & $1.51 \pm 0.44$ & $2.49 \pm 0.49$ & & $1.01 \pm 0.58$ & $1.84 \pm 0.35$ \\
$\quad$ Right atrial & $0.65 \pm 0.86$ & $1.49 \pm 0.72$ & $0.61 \pm 0.37$ & $1.04 \pm 0.74$ \\
\hline
\end{tabular}

Table 6. Systemic arterial blood gases, Hb oxygen saturation, and oxygen content in absence (-) and presence (+) of oxygen ventilation

\begin{tabular}{lcc}
\hline & $-\mathrm{O}_{2}$ ventilation & $+\mathrm{O}_{2}$ ventilation \\
\hline $\mathrm{pH}$ & $7.36 \pm 0.04$ & $7.34 \pm 0.08$ \\
$\mathrm{PCO}_{2}(\mathrm{kPa})$ & $7.26 \pm 0.65$ & $6.96 \pm 0.74$ \\
$\mathrm{PO}_{2}(\mathrm{kPa})$ & $2.70 \pm 0.54$ & $16.86 \pm 15.05^{*}$ \\
$\mathrm{Hb} \mathrm{O}_{2}$ saturation & $39.80 \pm 13.99$ & $93.43 \pm 6.43^{*}$ \\
$\mathrm{O}_{2}$ content $\left(\mathrm{mL} \mathrm{O}_{2} / \mathrm{L}\right)$ & $61.62 \pm 23.63$ & $136.83 \pm 21.42^{*}$ \\
\hline
\end{tabular}

${ }^{*} p<0.001$.

of the sacroplasmic reticulum (17-21), and underdevelopment of the $\beta$-receptor/adenylate cyclase complex $(22,23)$. However, mechanisms that are thought to accelerate myocardial maturity at birth, such as surges in thyroid hormone (23), cannot be functional in this preparation, and isoproterenol, the only intervention that should increase contractility in a manner similar to the postnatal catecholamine surge (37), only modestly increased output $(36 \%)$. In contrast, oxygen ventilation doubled left ventricular output. Thus, although the fetal myocardium is immature relative to that of the adult, it does not appear to be functionally immature relative to neonatal myocardium.

Heart rate changes have also been considered to be important in the increase in left ventricular output at birth (14). In our study, however, the majority of the increase in output occurred during oxygen ventilation alone, which had no effect on heart rate. It is important to note that our study was performed during parasymptomatic blockade, so that the control heart rates were far higher than those seen in the normal fetus. Thus, an increase in heart rate might have further increased left ventricular output, both directly and by increasing contractility via the Bowditch effect.

To speculate on the mechanisms whereby we found such a large increase in output, we must turn to other determinants of output: contractility, preload, and afterload. Although the newborn has only a limited contractile reserve $(8,48)$, the fetus has been shown to have a greater one, as demonstrated by significantly greater postextrasystolic potentiation in both isolated muscle strips and the in vivo heart (48). Although this may be part of the effect of isoproterenol in our study, it is unlikely that there was an increase in contractility during oxygen ventilation in the absence of an increase in heart rate. In contrast, oxygen ventilation does cause a large increase in left atrial pressure (3) similar to that seen at birth (6). It is thus likely that the large increase in left ventricular output in our study can be attributed to the Frank-Starling mechanism. That mechanism has been shown to be of very limited importance in the fetus (13), unless afterload does not increase (32). This may be the case in our study, inasmuch as left ventricular output increased nearly 3-fold during oxygen ventilation and isoproterenol infusion in the absence of an increase in aortic pressure. Perhaps an even more likely mechanism that unmasked the Starling response is a blunting of the effects of the right ventricle on left ventricular filling and ejection. The fetal right ventricle not only fills at the same or higher pressure than the left but also fills to almost twice the volume, and may constrain filling of the relatively stiff left ventricle (49). The onset of oxygen ventilation increases pulmo- nary venous return from about 8 to at least $50 \%$ of combined ventricular output (3), and left atrial pressure increases well above right. Thus, the right ventricular constraint of left ventricular filling should decrease, and left ventricular compliance, and thus end-diastolic volume, should increase substantially with the increase in left atrial pressure. Lastly, it should be appreciated that the fetal right ventricle may constrain left ventricular systolic performance as well. The fetal right ventricle is very sensitive to changes in afterload: an increase in central impedance by occlusion of the ductus arteriosus nearly halves its output (4). Although peak systolic right ventricular pressure does not decrease immediately at the onset of oxygen ventilation, the impedance of the vascular tree into which it is ejecting may. The large, low resistance pulmonary vascular bed into which it is ejecting at the onset of oxygen ventilation may cause more rapid emptying of the ventricle and limits its effects on left ventricular contraction.

In summary, we have found that the fetal left ventricle is capable of greatly increasing its output when it is exposed to a simulated postnatal circulatory environment, as modeled in this study by in utero oxygen ventilation, isoproterenol infusion, and volume loading. Although the fetal myocardium is immature compared with that of the adult, much of the increase in output that occurs at birth can be explained by the onset of oxygen ventilation and the increase in catecholamine levels. We speculate that these events unmask the Starling response by a combination of a decrease in left ventricular afterload and a blunting in right ventricular diastolic and systolic constraint of left ventricular performance, and by an increase in myocardial contractility. These data help to explain why the prematurely born infant is capable of handling large volume loads associated with reversal of blood flow through the ductus arteriosus despite the absence of the putative maturation of myocardium occurring in the term fetus around birth.

\section{REFERENCES}

1. Anderson DF, Bissonnette JM, Faber JJ, Thornburg KL 1981 Central shunt flows and pressures in the mature fetal lamb. Am J Physiol 241:H60-H66

2. Heymann MA, Creasy RK, Rudolph AM 1973 Quantitation of blood flow pattern in the foetal lamb in utero. In: Proceedings of the Sir Joseph Barcroft Centenary Symposium: Foetal and Neonatal Physiology. Cambridge University Press, Cambridge, UK, pp 129-135

3. Teitel DF, Iwamoto HS, Rudolph AM 1987 Effects of birth-related events on central blood flow patterns. Pediatr Res 22:557-566

4. Reller MD, Morton MJ, Reid DL, Thornburg KL 1987 Fetal lamb ventricles respond differently to filling and arterial pressures and to in utero ventilation. Pediatr Res 22:621-626

5. Sidi D, Kuipers JRG, Heymann MA, Rudolph AM 1983 Effects of ambient temperature on oxygen consumption and the circulation in newborn lambs at rest and during hypoxemia. Pediatr Res 17:254-258

6. Klopfenstein HS, Rudolph AM 1978 Postnatal changes in the circulation and responses to volume loading in sheep. Circ Res 42:839-845

7. Minoura S, Gilbert RD 1987 Postnatal change of cardiac function in lambs: effects of ganglionic block and afterload. J Dev Physiol 9:123-135

8. Teitel DF, Sidi D, Chin T, Brett C, Heymann MA, Rudolph AM 1985 Developmental changes in myocardial contractile reserve in the lamb. Pediatr Res 19:948-955

9. Lister G, Walter TK, Versmold HT, Dallman PR, Rudolph AM 1979 Oxygen delivery in lambs: cardiovascular and hematologic development. Am J Physiol 237:H668-H675.

10. Romero TE, Friedman WF 1979 Limited left ventricular response to volume overload in the neonatal period: a comparative study with the adult animal. Pediatr Res 13:910-915

11. Berman Jr W, Musselman J 1979 Myocardial performance in the newborn lamb. Am J Physiol 237:H66-H70

12. Riemenschneider TA, Brenner RA, Mason DA 1981 Maturational changes in myocardial contractile state of newborn lambs. Pediatr Res 15:349-356

13. Gilbert RD 1980 Control of fetal cardiac output during changes in blood volume. Am J Physiol 238:H80-H86.

14. Anderson PAW, Glick KL, Killam AP, Mainwaring RD 1986 The effect of heart rate on in utero left ventricular output in the fetal sheep. J Physiol 372:557-573

15. Rudolph AM, Heymann MA 1970 Circulatory changes during growth in the fetal lamb. Circ Res 26:289-299

16. Picardo S, Li C, Tundall M, Rudolph AM 1986 Fetal cardiovascular response to beta adrenoreceptor (BAR) stimulation. Pediatr Res 20:371 A(abstr)

17. Maylie JG, Thornburg KL, Faber JJ 1978 Force-frequency relations of the neonatal cat heart. In: Longo LD, Reneau DD (eds) Circulation in the Fetus and Newborn. Garland, New York, pp 391-398 
18. Maylie JG 1982 Excitation-contraction coupling in neonatal and adult myocardium of cat. Am J Physiol 242:H834-H843

19. Nakanishi $T$, Okuda $H$, Kamata $K$, Abe A, Sekiguchi M Takao A 1987 Development of myocardial contractile system in the fetal rabbit. Pediatr Res 22:201-207

20. Mahony L, Jones LR 1986 Developmental changes in cardiac sarcoplasmic reticulum in sheep. $\mathrm{J}$ Biol Chem 261:15257-15265

21. Mahony L 1988 Maturation of calcium transport in cardiac sarcoplasmic reticulum. Pediatr Res 24:639-643

22. Shaddy RE, Mak C, Bristow MR 1989 Comparative in vitro myocardial inotropic effects and in vivo hemodynamic effects of forskolin and isoproterenol in young lambs. Pediatr Res 25:580-584

23. Breall JA, Rudolph AM, Heymann MA 1984 Role of thyroid hormone in postnatal circulatory and metabolic adjustments. J Clin Invest 73:14181424

24. Friedman WF 1973 The intrinsic physiologic properties of the developing heart. In: Friedman WF, Lesch M, Sonnenblick EH (eds) Neonatal Heart Disease, Grune \& Stratton, New York, pp 21-49

25. Sheldon CA, Friedman WF, Sybers HD 1970 Scanning electron microscopy of fetal and neonatal lamb cardiac cells. J Molec Cell Cardiol 8:853-862

26. Clyman RI, Murray F, Heymann MA, Roman C 1987 Cardiovascular effects of patent ductus arteriosus in preterm lambs with respiratory distress. J Pediatr 111:579-587

27. Clyman R, Teitel D, Padbury J, Roman C, Mauray F 1988 The role of $\beta$ adrenergic stimulation and contractile state in the preterm lamb's response to altered ductus arteriosus patency. Pediatr Res 23:316-322

28. Padbury J, Agata Y, Ludlow J, Ikegami M, Baylen B, Humme J 1987 Effect of fetal adrenalectomy on catecholamine release and physiologic adaptation at birth in sheep. J Clin Invest 80:1096-1103

29. Lindner WL, Siedel M, Versmold HT, Dohlemann C, Riegel KP 1990 Stroke volume and left ventricular output in preterm infants with patent ductus arteriosus. Pediatr Res 27:278-281

30. Morton MJ, Pinson CW, Thornburg KL 1987 In utero ventilation with oxygen augments left ventricular stroke volume in lambs. J Physiol 383:413-424

31. Minczak BM, Wolfson MR, Santamore WP, Shaffer TH 1988 Developmental changes in diastolic ventricular interaction. Pediatr Res 23:466-469

32. Hawkins J, Van HG, Schmidt KG, Rudolph AM 1989 Effects of increasing afterload on left ventricular output in fetal lambs. Circ Res 65:127-134
33. Belenkie I, Dani R, Smith ER, Tyberg JV 1988 Ventricular interaction during experimental acute pulmonary embolism. Circulation 78:761-768

34. Belenkie I, Dani R, Smith ER, Tyberg JV 1989 Effects of volume loading during experimental acute pulmonary embolism. Circulation 80:178-188

35. Lavine SJ, Tami L, Jawad I 1988 Pattern of left ventricular diastolic filling associated with right ventricular enlargement. Am J Cardiol 62:444-448

36. Sholler GF, Colan SD, Sanders SP 1988 Effect of isolated right ventricular outflow obstruction on left ventricular function in infants. Am J Cardiol 62:778-784

37. Padbury JF, Diakomanolis ES, Nobel CJ, Perelman A, Fisher DA 1981 Neonatal adaptation: sympatho-adrenal response to umbilical cord cutting. Pediatr Res 15:1483-1487

38. Iwamoto HS, Rudolph AM 1983 Chronic renal venous catheterization in fetal sheep. Am J Physiol 245:H524-H527

39. Iwamoto HS, Teitel DF, Rudolph AM 1987 Effects of birth-related events on blood flow distribution. Pediatr Res 22:634-640

40. Slinker BK, Glantz SA 1990 Missing data in two-way analysis of variance. Am J Physiol 258:R291-R297

41. Glantz SA, Slinker BK 1990 Primer of Applied Regression and Analysis of Variance. McGraw-Hill, New York

42. Slinker BK, Glantz SA 1985 Multiple linear regression is a useful alternative to traditional analyses of variance. Am J Physiol 255:R1-R12

43. Boltwood Jr CM, Appleyard RF, Glantz SA 1989 Left ventricular volume measurement by conductance catheter in intact dogs: parallel conductance volume depends on left ventricular size. Circulation 80:1360-1377

44. Zar JH 1984 Biostatistical Analysis. Prentice-Hall, Englewood, NJ

45. Rudolph AM, Heymann MA 1976 Cardiac output in the fetal lamb: the effects of spontaneous and induced changes of heart rate on right and left ventricular output. Obstet Gynecol 124:183-192

46. Teitel DF 1988 Circulatory adjustments to postnatal life. Semin Perinatol 12:96-103

47. Rudolph AM 1986 Venous return and cardiac output in the perinatal period In: Cardiovascular and respiratory physiology in the fetus and neonate, Vol 133. Colloque INSERM/John Libbey Eurotext Ltd, Paris, pp 15-30

48. Anderson PA, Glick KL, Manring A, Crenshaw CJ 1984 Developmental changes in cardiac contractility in fetal and postnatal sheep: in vitro and in vivo. Am J Physiol 247: H371-H379

49. Romero T, Covell J, Friedman WF 1972 A comparison of pressure-volume relations of the fetal, newborn, and adult heart. Am J Physiol 222:12851290 